\title{
Isolation of Alveolar Type II Cells from Adult Bovine Lung
}

\author{
Diane Frances Lee ${ }^{1,2}$ and Mark Andrew Chambers ${ }^{1}$ \\ ${ }^{1}$ School of Veterinary Medicine, University of Surrey, Guildford, Surrey, United Kingdom \\ ${ }^{2}$ Corresponding author: diane.lee@surrey.ac.uk
}

\begin{abstract}
Alveolar type II (ATII) cells play a key role as part of the distal lung epithelium, including in the innate immune response and as self-renewing progenitors to replace alveolar type I (ATI) cells during epithelial regeneration. Their secretion of surfactant protein helps maintain homeostasis and exerts protective, antimicrobial properties. ATII cells remain difficult to study, partly due to inefficient and expensive isolation methods, a propensity to differentiate into ATI cells, and susceptibility to fibroblast contamination. Published methods of isolation often require specialized technology, negatively impacting the development of in vitro models of disease, including bovine tuberculosis. Presented here is a simple and cost-effective method for generation of bovine primary ATII cells. These cells exhibit an ATII phenotype in 2D and 3D culture and are conducive to further study of the role of ATII cells in bovine respiratory diseases. () 2019 by John Wiley \& Sons, Inc.
\end{abstract}

Keywords: alveolus $\bullet$ ATII $\bullet$ bovine $\bullet$ epithelial $\bullet$ isolation

\section{How to cite this article:}

Lee, D. F., \& Chambers, M. A. (2019). Isolation of alveolar type II cells from adult bovine lung. Current Protocols in Toxicology, e71. doi: 10.1002/cptx.71

\section{INTRODUCTION}

The alveoli are specialized regions of the distal lung, with a morphology that is favorable to efficient gaseous exchange. Two types of epithelial cell line the alveolus. Alveolar type I (ATI) cells exhibit a broad, flattened morphology and cover around $95 \%$ of the alveolus surface area, whereas alveolar type II (ATII) cells are cuboidal and line the remainder of the alveolus (Fujino et al., 2011). ATI cells provide a gas exchange interface with the underlying endothelium, whereas ATII cells serve as progenitors of ATI cells and also play a critical role in maintaining the homeostasis of the alveolus (Driscoll et al., 1995; Fehrenbach, 2001).

The ATII cell is the only epithelial cell of the lung that synthesizes and releases all four surfactant proteins $\mathrm{A}, \mathrm{B}, \mathrm{C}$, and $\mathrm{D}$, with surfactant protein $\mathrm{C}$ being unique to the ATII cell (Phelps \& Floros, 1991). Studies utilizing ATII cells or cell lines derived from them are vital to the elucidation of host-pathogen interactions, including diseases falling under the One Health remit, such as tuberculosis, in the top ten causes of death worldwide (WHO, 2017). The causative agent of bovine tuberculosis (BTB), Mycobacterium bovis, can cause progressive disease in most warm-blooded mammals, and the WHO estimates that $3.1 \%$ of all human cases of tuberculosis are caused by BTB (WHO, 2017). New in vitro models of the alveolus are required to enable comparative studies between species and evaluate the role of ATII cell in the initial stages of BTB pathogenesis. 
Evaluating the role of ATII cells in bovine pulmonary diseases such as BTB requires an efficient method of isolating ATII cells. This article describes a simple ATII cell isolation technique from cattle of less than 24 months. No specialized equipment is required (as with flow cytometry or magnetic separation). The full protocol combines dissection, mincing, and enzymatic digestion (see Basic Protocol 1), selective adherence (see Basic Protocol 2), and gradient centrifugation (see Basic Protocol 3). This approach results in a predominantly epithelial cell population $(85-90 \%)$ that exhibits an ATII phenotype (Lee et al., 2018) together with 10-15\% fibroblasts. The latter may be removed for downstream applications by cold trypsinization (see Basic Protocol 4).

\section{STRATEGIC PLANNING}

The success of isolating ATII cells using this method is dependent on robust logistics being in place. If there are no animals available onsite, a working relationship with a local slaughter facility is required. All solutions may be prepared a day in advance, with the exception of the digestion solution, which contains temperature-sensitive enzymes and should therefore be prepared on the day of use. It is also recommended that bovine IgG-coated plates be prepared the day before use and stored at $2-8^{\circ} \mathrm{C}$ with the coating solution in situ.

BASIC PROTOCOL 1

Lee and Chambers

\section{DIGESTION OF DISTAL LUNG TISSUE TO GENERATE A MIXED POPULATION OF CELLS}

The initial step in the isolation process is the mincing of distal lung tissue and enzymatic digestion to generate a mixed population of cells. Lungs may be supplied by a local slaughter or fallen stock facility from cattle that are health-screened at the point of slaughter by the attending veterinary surgeon. Animals showing signs of acute respiratory distress or clinical signs such as coughing or excessive nasal discharge at this stage should be excluded on the basis that cells from such animals represent an increased risk of cell contamination (particularly fungal) for both isolated cells arising from this procedure and other cells cultured in the facility. For consistency, approximately $100 \mathrm{~g}$ of tissue is removed from the right distal lobe. An addition sample of right distal lobe tissue is reserved for histological analysis by a veterinary pathologist to confirm the healthy status of the tissue. Ear tag numbers may be noted for each animal used for disease surveillance purposes.

The tissue is first minced and then washed to remove residual connective tissue, blood cells, and vessels. This increases the purity of the isolated population, and the antibiotics used reduce the likelihood of bacterial contamination. The minced tissue is then digested in a mixture of enzymes optimized for bovine lung tissue. The recipe in this protocol is adapted from Mao et al. (2015).

\section{Materials}

Right distal lung, acquired as part of a tracheal 'pluck', from cattle $<24$ months old Wash solutions A-C (see recipe)

Digestion solution (see recipe)

Neutralization solutions (see recipe)

$10 \%(\mathrm{v} / \mathrm{v})$ neutral buffered formalin (NBF, optional)

5\% Virkon disinfectant solution

Adhesion solution (see recipe)

$70 \%(\mathrm{v} / \mathrm{v})$ industrial methylated spirits (for sterilizing tools)

Class II microbiological safety cabinet (MBSC)

UV lamp (recommended) 


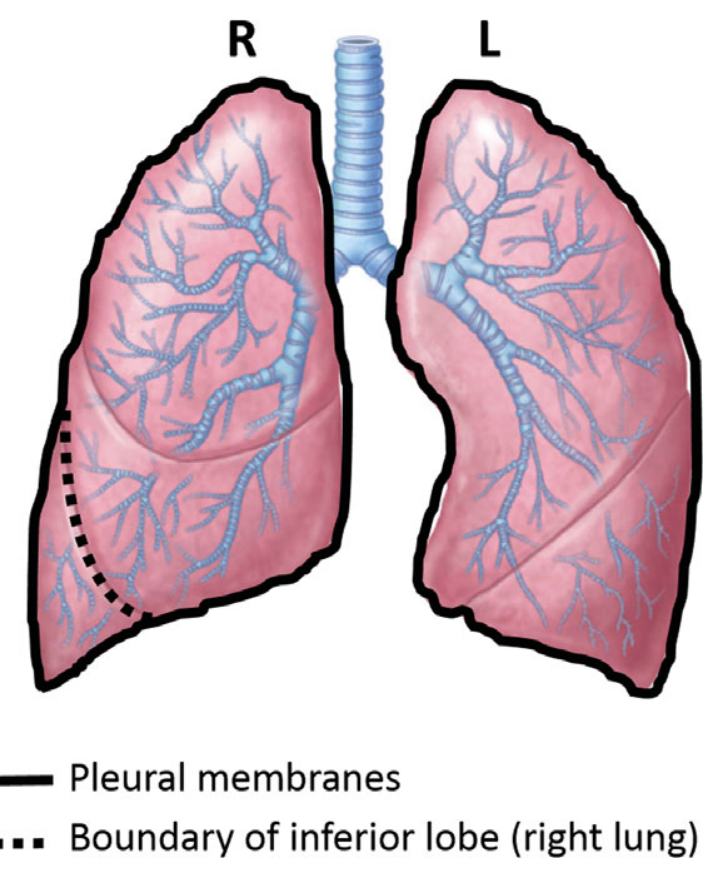

Figure 1 Anatomy of the bovine lung. The distal (inferior) lung is taken for isolation of alveolar type II cells (dashed line). Prior to digestion, it is first necessary to remove the outer (pleural) membranes that completely surround the lung.

Sterile bag

Sterile carving knife

Dissection instruments: sterile scalpels, forceps, and scissors

15-cm sterile Petri dish

Sterile 50-ml graduated tubes

5-liter waste container with lid

Tube rocker or rotator

Matrix Filter Cell MicroSieve, 25-, 50-, and 100- $\mu \mathrm{m}$ pore size (Fisher)

Large funnel ( $>20 \mathrm{~cm}$ diameter)

Sterile glass beakers (one for each filtration step)

NOTE: All solutions should be stored at $2-8^{\circ} \mathrm{C}$ until use. All centrifugation steps are performed at $4^{\circ} \mathrm{C}$. Enzymatic digestion should be performed at $37^{\circ} \mathrm{C}$.

\section{Dissect and wash lung tissue}

1. On the day of isolation, assemble wash solutions A-C and add DNase I to neutralization and adhesion solutions. Prepare fresh digestion solution. Cool all solutions to $2-8^{\circ} \mathrm{C}$.

2. Set up dissection area in an MBSC. For additional biosecurity, switch on a UV light, if available.

3. Retrieve lungs from point of slaughter, ideally in a sterile bag containing solution A. Remove the distal third of the right lobe (the inferior lobe; Fig. 1) using a sterile carving knife. Transport to the MBSC in solution A ( $\sim 1$ liter).

At this point, a veterinary pathologist may be employed to perform gross examination of the lungs received to ensure the absence of clinical signs of respiratory disease in the animal. 
4. In the MBSC, use a scalpel to remove $1 \mathrm{~cm}^{3}$ tissue for histological analysis by a veterinary pathologist, if required. Place the sample into a suitable vessel containing $10 \%$ NBF.

5. Add $5 \mathrm{ml}$ wash solution B to a $15-\mathrm{cm}$ sterile Petri dish to keep the dissected tissue moist. Remove the pleural membranes using a scalpel, then take $\sim 1-\mathrm{cm}^{3}$ pieces of lung tissue and use scissors and a scalpel to mince them to $\sim 1-\mathrm{mm}^{3}$ pieces. Transfer pieces to 50-ml sterile tubes, filling each to the $10-\mathrm{ml}$ mark with minced tissue.

It is recommended to use both the dish and the inverted lid, adding solution $B$ to each.

A minimum of eight 50-ml tubes is typically needed for $100 \mathrm{~g}$ tissue.

6. Fill each tube to the 40-ml mark with wash solution C. Shake vigorously for $1 \mathrm{~min}$ and then discard the supernatant into 5\% Virkon disinfectant solution in a 5-liter waste container. Repeat until the supernatant is clear (at least eight washes).

If the tissue floats, it may be more practical to aspirate the supernatant from below with a serological pipette.

\section{Digest and filter tissue}

7. Add $20 \mathrm{ml}$ digestion solution to each $50-\mathrm{ml}$ tube and agitate by rocking or rotating at $37^{\circ} \mathrm{C}$ for $60 \mathrm{~min}$.

8. Neutralize enzymatic activity by adding $20 \mathrm{ml}$ neutralization solution and rocking briefly to mix.

9. Filter pieces sequentially through a $100-, 50-$, and $25-\mu \mathrm{m}$ filter membrane by overlaying the membrane onto a funnel. Collect the crude cell suspension in a sterile beaker and divide between 50-ml tubes.

10. Spin at $300 \times g$ for $10 \mathrm{~min}$ at $4^{\circ} \mathrm{C}$.

11. Resuspend in $40 \mathrm{ml}$ adhesion solution and proceed immediately to Basic Protocol 2.

BASIC PROTOCOL 2

\section{REMOVAL OF MACROPHAGES AND FIBROBLASTS BY SELECTIVE ADHERENCE}

This technique is based on the panning method published by Wysocki and Sato (1978) as a method of fractionating T and B lymphocytes and applied by Dobbs, Gonzalez, and Williams (1986) to isolation of ATII cells from rat lung. The method is based upon the ability of antibody molecules to simultaneously adhere to polystyrene surfaces and bind antigen. Here it is used to also reduce the number of contaminating fibroblasts, which have previously been reported to show a greater affinity for bacterial grade polystyrene (Ehrhardt, Kim, \& Lehr, 2005). Plates may be coated overnight at $2-8^{\circ} \mathrm{C}$ or for $40 \mathrm{~min}$ at room temperature under sterile conditions.

\section{Materials}

Gamma globulin (IgG) from bovine serum (Sigma)

$0.05 \mathrm{M}$ Tris buffer, $\mathrm{pH} 9.5$ (Fisher), filter sterilized $(0.2-\mu \mathrm{m})$

Centrifugation solution (see recipe)

Wash solution $\mathrm{C}$ (see recipe)

Digested cell suspension in adhesion solution (see Basic Protocol 1)

$150 \times 15-\mathrm{mm}$ bacterial grade polystyrene Petri dishes

$37^{\circ} \mathrm{C}$ incubator 
1. In the MBSC, add IgG from bovine serum to Tris buffer at a final concentration of $5 \mu \mathrm{g} / \mathrm{ml}$. Add DNase I to centrifugation solution.

2. Overlay six Petri dishes with $10 \mathrm{ml}$ IgG solution and swirl to distribute evenly. Let sit at room temperature for $40 \mathrm{~min}$ or overnight at $2-8^{\circ} \mathrm{C}$.

Coating overnight at $2-8^{\circ} \mathrm{C}$ is recommended for ease of logistics, but both methods may be used with equal success.

3. Remove IgG solution and gently rinse dishes twice with wash solution C.

4. Pour $10 \mathrm{ml}$ cell suspension onto each plate and swirl to ensure coverage. Incubate at $37^{\circ} \mathrm{C}$ for $1 \mathrm{hr}$, rocking mid-way through the incubation to redistribute cells.

A maximum of $9 \times 10^{7}$ cells should be added to each 150-mm Petri dish $\left(9 \times 10^{6}\right.$ cells $/ \mathrm{ml}$ ). If the cell count exceeds this amount, the volume of adhesion solution used to resuspend the cell pellet should be adjusted accordingly and more IgG-coated Petri dishes used.

5. Collect supernatant containing non-adherent cells, consolidating it in 50-ml tubes.

6. Centrifuge at $300 \times g$ for $10 \mathrm{~min}$ at $4^{\circ} \mathrm{C}$. Resuspend in $8 \mathrm{ml}$ centrifugation solution, combining all pellets into a single suspension, and proceed immediately to Basic Protocol 3.

DNase I should be added to centrifugation solution fresh before each use.

\section{GENERATION OF ENRICHED ATII FRACTION BY PERCOLL GRADIENT CENTRIFUGATION}

The Percoll reagent was first formulated by Pertoft, Laurent, Låås, and Kågedal (1978). When poured as a density gradient, it separates cells or particles using the principle of isopycnic separation. During centrifugation, particles or cells will settle where their density has reached equilibrium with the density of the surrounding medium. Density gradients of this nature have been successfully used numerous times in previous studies where ATII cells have been isolated (Gonzalez \& Dobbs, 2013; Mao et al., 2015; also reviewed by Dobbs, 1990). The use of a three-phase Percoll gradient $(4 \%, 10 \%$, and $30 \%)$ results in an enriched band of ATII cells at the interface of the $10 \%$ and $30 \%$ phases. This is removed and resuspended in small airway growth medium to dilute the Percoll and allow pelleting by centrifugation. Finally, the cell pellet is resuspended and used to establish cultures and determine phenotype by immunofluorescent staining of ATII cell markers (Lee et al., 2018).

\section{Materials}

Light and heavy Percoll gradient solutions (see recipe)

Phenol red

Enriched cell suspension in 4\% Percoll (see Basic Protocol 2)

Centrifugation solution (see recipe)

Wash solution C (see recipe)

Small airway growth medium (SAGM)

Freezing medium (see recipe)

4\% (w/v) paraformaldehyde (Sigma)

DPBS (Fisher, 12037539)

$0.1 \%$ Triton $\mathrm{X}-100$ (Sigma) in DPBS

$5 \%$ normal serum in DPBS

Primary antibodies:

Rabbit anti-prosurfactant protein C (proSP-C) (ab3786, Millipore)

Mouse cytokeratin 18 (CK18) (sc32329, Santa Cruz Biotechnology)

BASIC

PROTOCOL 3
Lee and

Chambers 
Mouse anti-CD74, FITC conjugated (CD74-FITC) (sc47742, Santa Cruz

Biotechnology)

Appropriate fluorophore-labeled secondary antibodies

Aqueous mounting medium (optional)

15- and 50-ml centrifuge tubes

Tube stand

10-ml serological pipettes

Benchtop centrifuge with swinging-bucket rotor (e.g., Eppendorf 5810R)

$1000-\mu 1$ pipette

Trypan blue

Automated cell counter or hemocytometer

T25 and T75 tissue culture flasks

$37^{\circ} \mathrm{C}$ incubator

Cryovials (Nunc)

Chambered coverglass (Nunc)

Inverted microscope

Microscope slides (optional)

\section{Pour Percoll gradients}

1. Prepare desired amounts of light and heavy Percoll gradient solutions (10\% and $30 \%$ ). Add two drops of phenol red to the heavy solution.

2. Place eight $15-\mathrm{ml}$ centrifuge tubes on a stand. Without touching the sides of the tubes (i.e., filling from the bottom up), add $6 \mathrm{ml}$ heavy solution to each tube. Avoid introducing bubbles.

3. Gently overlay $8 \mathrm{ml}$ light solution onto the heavy solution in the first tube (Fig. 2A) as follows:

a. Aspirate a little $>8 \mathrm{ml}$ of light solution into a 10-ml serological pipette.

b. Holding the end of the pipette over a waste vessel, remove the pipette filler and quickly seal the top of the pipette using the thumb (Fig. 2B). Then, release the thumb slightly and allow the light solution to drain by gravity until the 8-ml mark is reached.

c. Move the pipette to the gradient tube. Hold the tube at a $30^{\circ}$ angle and very slightly move the thumb to release a little of the solution (a drop or so), allowing the drop to run down the inside of the tube.
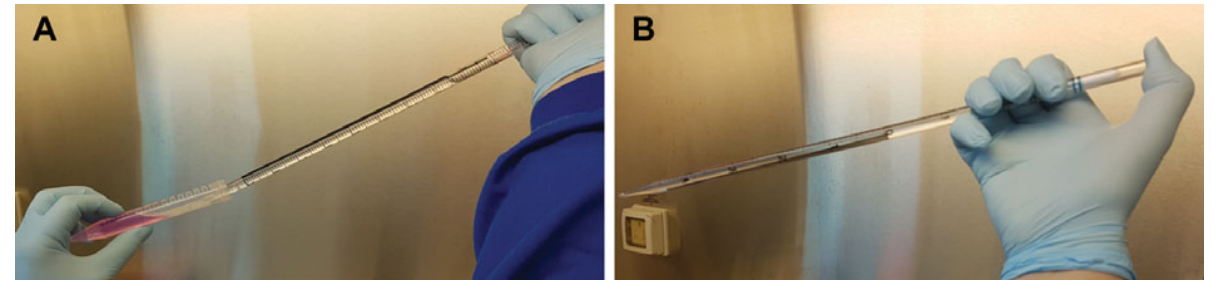

Figure 2 Preparation of a Percoll gradient. The first stage involves the bottom-up pouring of the heavy $(30 \%)$ fraction by holding the serological pipette tip at the base of the tube and raising it as the liquid is dispensed. This avoids introduction of bubbles. The tube is then inclined at $30^{\circ}$ for the overlaying of the light (10\%) fraction $(\mathbf{A})$, which is executed by extremely gentle release of the thumb's seal at the top of the pipette $(\mathbf{B})$. Upon completion of Percoll gradient centrifugation, there should be a milky white band at the interface of the $10 \%$ and $30 \%$ fractions, which will contain a cell population enriched for ATII. 
d. Repeat until multiple drops have joined to create the 10-30\% Percoll interface. Continue to overlay the light gradient solution in this way until all $8 \mathrm{ml}$ have been applied.

Allowing too much solution to dispense will disturb the interface. The phenol red in the heavy fraction allows easy visualization of the interface. A clear line should be seen. If a clear line cannot be observed, the gradient should be discarded.

4. Repeat with remaining tubes.

It is best to prepare Percoll gradients immediately before use, during the adherence phase of the isolation protocol.

\section{Perform gradient centrifugation}

5. Gently overlay $1 \mathrm{ml}$ cell suspension on the top of each tube, so that a clear line forms at the interface between the $4 \%$ uppermost layer and the $10 \%$ fraction. Keep tubes upright at this stage and avoid knocking them.

6. Centrifuge at $400 \times g$ for $20 \mathrm{~min}$ at $4^{\circ} \mathrm{C}$ using a swinging-bucket rotor. Set acceleration on the lowest setting and the brake off.

Braking should be off because it is important not to disturb the gradient. If this function is not available, switch the centrifuge off manually and allow it to slow naturally to a halt before switching it back on to retrieve samples.

Unless the gradient has been disturbed during pouring or centrifugation, a milky white band forms at the interface between the 10\% and 30\% phases and contains an enriched layer of ATII cells.

7. Remove the entire gradient by careful pipetting, $1 \mathrm{ml}$ at a time, working from the top down. Pool fractions from all eight gradients into 4\%, 10\%, interface (ATII cells), $30 \%$, and pellet fractions in 50-ml tubes. To confirm successful enrichment, keep all fractions.

Removal of the interface region should include $\sim 1 \mathrm{ml}$ on either side of the white band of cells. Removal of the band is most effective when slowly moving the pipette tip around the perimeter of the band while aspirating. To ensure no cells are lost, all fractions should be kept until ATII cells have been identified by morphology and biomarkers.

8. Dilute each fraction in wash solution $\mathrm{C}$ to lower the Percoll concentration to below $10 \%$.

This is necessary to enable pelleting without generating excess shear forces.

9. Spin each fraction at $300 \times g$ for $10 \mathrm{~min}$ at room temperature. Perform a viable cell count by trypan blue exclusion and resuspend each pellet to no less than 300,000 cells/ml in SAGM. Proceed simultaneously to culturing and phenotyping by immunostaining.

The expected yield is $\sim 6 \times 10^{6}$ cells.

\section{Culture cells}

10. Seed $2.5 \times 10^{5}$ or $7.5 \times 10^{5}$ isolated cells into T25 or T75 tissue culture flasks, respectively, and grow in a $37^{\circ} \mathrm{C}$. Monitor for fungal or bacterial growth under a light microscope. To maintain high density, passage ATII cells up to 1:4 when they reach $75-80 \%$ confluence. At time of passage, freeze stocks in freezing medium at a concentration of $1,000,000$ cells $/ \mathrm{ml}$.

Typically, ATII primary cells may be cultured in SAGM for 10-12 passages before senescence. Splits greater than 1:4 are not recommended, as they will result in growth arrest. 
ATII cells freeze well, maintaining a viability of greater than $90 \%$ upon thawing. One vial (containing 1 million cells/ml) can be thawed, diluted directly into $7 \mathrm{ml} S A G M$, and plated onto a T25 tissue culture flask using routine culture conditions.

ATII cells readily differentiate into ATI cells when cultured submerged on $2 D$ plastic. This differentiation appears to be reversible, as previously reported by Wang et al. (2007) and observed in our own studies. To maintain the ATII phenotype, it is recommended that ATII cells be cultured at an air-liquid interface or as $3 D$ cultures, as described by (Lee et al., 2013).

\section{Confirm ATII phenotype}

11. Seed 3000 freshly isolated cells (or 1-2 days culture, if seeding onto uncoated surfaces) onto a chambered coverglass and grow overnight.

12. Fix 1-day-old cultures for $30 \mathrm{~min}$ in $4 \%$ paraformaldehyde, then permeabilize for 10 min in $0.1 \%$ Triton $\mathrm{X}-100$ in DPBS.

13. Block nonspecific staining with 5\% normal serum/95\% DPBS for $30 \mathrm{~min}$.

14. Incubate with primary antibodies diluted $1: 100$ in blocking buffer overnight at $4{ }^{\circ} \mathrm{C}$.

anti-prosurfactant protein $\mathrm{C}$

anti-cytokeratin 18

FITC-conjugated anti-CD74

15. Wash cells $3 \times 5$ min with DPBS.

16. Incubate with fluorophore-labeled secondary antibody for $1 \mathrm{hr}$ at room temperature.

Suitable fluorophores include Alexa Fluor 488 and 594.

17. Wash as before.

18. Visualize directly using an inverted microscope or mount in aqueous medium on a microscope slide for visualization at a later time.

Morphological features characteristic of ATII cells include lamellar inclusion bodies. These may be demonstrated by modified Papanicolaou staining as outlined in detail in Dobbs (1990). Like many other epithelial cells, ATII cells exhibit a cobblestone morphology at confluence. The cuboidal shape is observed only in cross-sections.

BASIC PROTOCOL 4

Lee and Chambers

\section{REMOVAL OF CONTAMINATING FIBROBLASTS FROM EPITHELIAL CULTURES}

Fibroblast contamination is a common problem in the culture of primary epithelial cells isolated from fresh tissue. Two previously published methods may be used to reduce fibroblast contamination (Pal \& Grover, 1983). The first exploits differential rates of detachment in the presence of cold trypsin. This enriches the culture for ATII cells considerably; however, epithelial cells also detach, thus depleting cell numbers considerably. Despite the removal of many epithelial cells in addition to fibroblasts, this method has merits for experiments requiring ultrapure cultures.

If a higher viable cell count is required, a relatively simple alternative can be employed. This method is based on relative susceptibility to treatment with HBSS. It results in the removal of fibroblasts and $>90 \%$ viability of the remaining epithelial cells.

The most distinguishable feature of fibroblasts is their spindle-like morphology. Fibroblasts are much longer than they are wide and produce a greater contrast against the tissue culture surface when visualized under a phase-contrast microscope (Fig. 3A). Epithelial cells exhibit a cobblestone morphology (Fig. 3B) and do not produce such a striking contrast. This makes contaminating fibroblasts easy to find in epithelial cell cultures. 


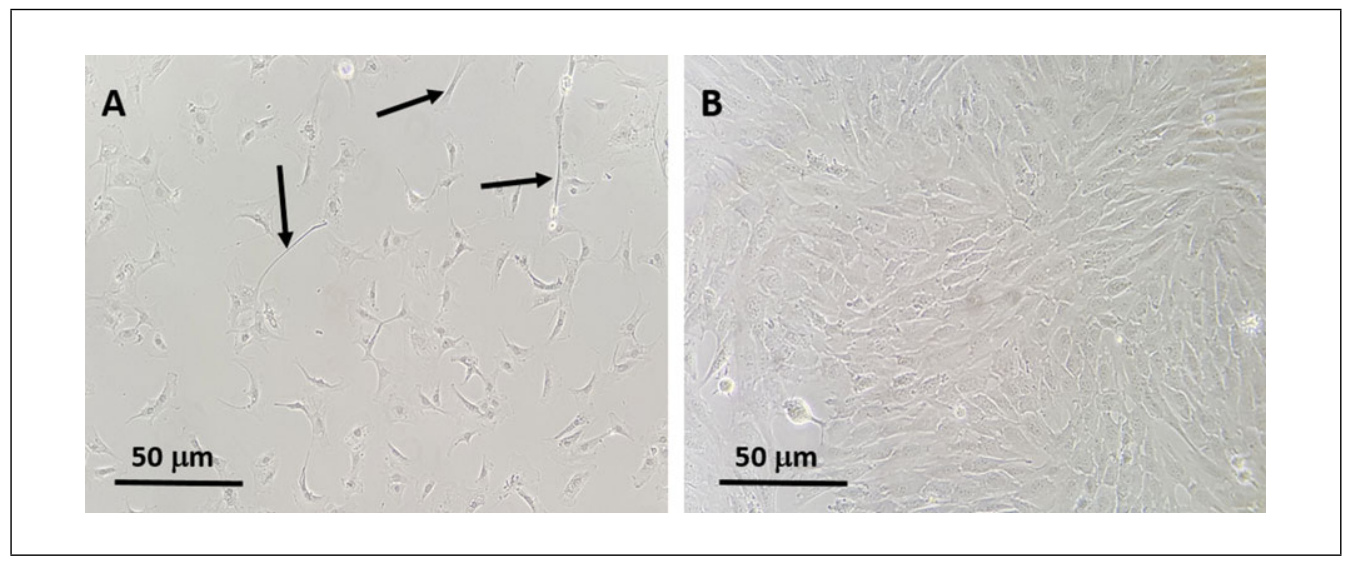

Figure 3 Fibroblast removal from ATII cultures. Fibroblasts are notable for their elongated spindle-like morphology (A, arrows). Following their removal, ATII cells exhibit a cobblestone morphology when allowed to grow to confluence $(\mathbf{B})$.

\section{Materials}

Cultured ATII cells (see Basic Protocol 3)

$0.25 \%$ trypsin

DMEM/F12/FBS: 1:1 (v/v) DMEM/F12 with glucose, glutamine, phenol red,

HEPES, and sodium pyruvate (Fisher) containing 10\% FBS (heat inactivated; Fisher)

DPBS, $\mathrm{Ca}^{2+} / \mathrm{Mg}^{2+}$ free (Fisher)

Small airway growth medium Bulletkit (Lonza, CC-3118)

Hanks' balanced salt solution (HBSS, Fisher)

Phase-contrast microscope

\section{Cold Trypsin Treatment}

1a. Remove cultures from incubator. Add ice-cold $0.25 \%$ trypsin to cultures $(1.5 \mathrm{ml}$ for a T25 flask or $3 \mathrm{ml}$ for a T75 flask) and leave in the MBSC for $2 \mathrm{~min}$.

2a. Remove supernatant containing contaminating fibroblasts (and some epithelial cells) and discard.

3a. Immediately wash remaining adhered cells with DMEM/F12/FBS to neutralize any remaining trypsin.

4a. Wash adhered cells with DPBS and feed with SAGM.

5a. Check cells under a microscope for density. If cells are $<20 \%$ confluent, add fresh warm $0.25 \%$ trypsin, neutralize as per routine passage procedure, and consolidate cultures in tissue culture flasks at a minimum density of 5000 cells $/ \mathrm{cm}^{2}$.

\section{HBSS Treatment}

1b. Remove cultures from incubator and wash twice with DPBS.

2b. Add HBSS ( $5 \mathrm{ml}$ for a T25 flask or $10 \mathrm{ml}$ for a T75 flask) and return flasks to incubator. Check cultures every 10-15 min under a microscope.

Detached fibroblasts are observed within 15 min of incubation in HBSS. The previous literature reports incubating for 2-3 hr. The majority of fibroblasts should be floating after 30 min incubation.

3b. When no attached fibroblasts are observed in the culture, remove supernatant containing contaminating fibroblasts and discard. 
4b. Wash cultures briefly with DPBS and feed as usual with SAGM. If density is below $20 \%$, passage cells as described in step 5 a.

\section{REAGENTS AND SOLUTIONS}

Use Milli-Q-purified water or equivalent in all recipes and protocol steps.

\section{Adhesion solution}

$100 \mathrm{ml} \mathrm{1:1} \mathrm{(v/v)} \mathrm{DMEM/Ham's} \mathrm{F12} \mathrm{(Fisher)}$

$100 \mathrm{ml}$ small airway growth medium (SAGM; Lonza, CC-3118)

$10 \mathrm{ml}$ FBS (heat inactivated; Fisher)

Filter sterilize $(0.2 \mu \mathrm{m})$

Store up to 1 month at $2-8^{\circ} \mathrm{C}$

Before use, add 2\% (w/v) DNase I ( $\geq 2000 \mathrm{KU} / \mathrm{mgP}$; Sigma, D5025)

\section{Centrifugation solution}

$10 \mathrm{ml}$ wash solution $\mathrm{C}$ (see recipe)

$4 \%$ (v/v) Percoll (Sigma)

$4 \%$ (v/v) FBS (heat inactivated; Fisher)

Store up to 1 month at $2-8^{\circ} \mathrm{C}$

Before use, add $0.01 \%$ (w/v) DNase I ( $\geq 2000 \mathrm{KU} / \mathrm{mgP}$; Sigma, D5025)

\section{Digestion solution}

$100 \mathrm{ml}$ DPBS

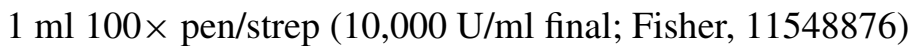

$0.008 \%(\mathrm{w} / \mathrm{v})$ porcine pancreas elastase (Fisher, 15484279)

$0.2 \%(\mathrm{w} / \mathrm{v})$ collagenase (Fisher, 15434789)

$0.005 \%$ (w/v) DNase I ( $\geq 2000 \mathrm{KU} / \mathrm{mgP}$; Sigma, D5025)

$0.05 \%(\mathrm{w} / \mathrm{v})$ trypsin (Fisher, 11560626)

Prepare under sterile conditions

Filter sterilize $(0.2 \mu \mathrm{m})$

Store at $2-8^{\circ} \mathrm{C}$ and use within $24 \mathrm{hr}$

\section{Freezing medium}

50\% 1:1 (v/v) DMEM/Ham's F12 (Fisher)

$40 \%$ FBS (heat inactivated; Fisher)

$10 \%$ DMSO (Sigma)

Store up to 1 month at $2-8^{\circ} \mathrm{C}$

\section{Neutralization solution}

$100 \mathrm{ml}$ 1:1 (v/v) DMEM/Ham's F12 (Fisher)

$25 \%$ (v/v) FBS (heat inactivated; Fisher)

Filter sterilize $(0.2 \mu \mathrm{m})$

Store up to 1 month at $2-8^{\circ} \mathrm{C}$

Before use, add 0.01\% (w/v) DNase I ( $\geq 2000 \mathrm{KU} / \mathrm{mgP}$; Sigma, D5025)

Percoll gradient solutions, light (10\%) and heavy (30\%)

$50 \mathrm{ml}$ wash solution $\mathrm{C}$ (see recipe)

$10 \%$ or $30 \%$ (v/v) Percoll (Sigma)

Store up to 1 month at $2-8^{\circ} \mathrm{C}$

\section{Wash solution $A$}

5 liters PBS (Oxoid tablets, Fisher, BR0014G)

Filter sterilize $(0.2 \mu \mathrm{m})$ 
Store up to 1 month at $2-8^{\circ} \mathrm{C}$

Compared to wash solution $C$, this solution uses PBS tablets to reduce cost during the dissection. However, DPBS can also be used.

\section{Wash solution B}

$500 \mathrm{ml}$ DPBS (Fisher, 12037539)

$5 \mathrm{ml} 500 \mathrm{mM}$ EDTA (Fisher, 10030140)

$5 \mathrm{ml} 100 \times \mathrm{pen} / \mathrm{strep}(10,000 \mathrm{U} / \mathrm{ml}$; Fisher, 11548876)

Filter sterilize $(0.2 \mu \mathrm{m})$

Store up to 1 month at $2-8^{\circ} \mathrm{C}$

\section{Wash solution $C$}

1 liter DPBS (Fisher, 12037539)

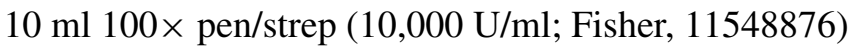

Filter sterilize $(0.2 \mu \mathrm{m})$

Store up to 1 month at $2-8^{\circ} \mathrm{C}$

\section{COMMENTARY}

\section{Background Information}

The study of early host-pathogen interactions between infectious agents and ATII cells is crucial to advancing our understanding of the pathogenesis of infectious respiratory disease in cattle, including bovine tuberculosis (BTB). Furthermore, the development of successful disease prevention and treatment strategies requires reliable in vitro models of the bovine alveolus, beginning with the consistent and efficient isolation of ATII cells. The methods outlined here are simple, reproducible, and cost-effective. They have wide implications, not least the possibility of transfer to other species and application by institutes lacking animal housing facilities or easy access to sophisticated equipment. In our hands, previously reported methods of isolating ATII cells, such as flow-activated cell sorting (FACS; Gereke et al., 2012) and magnetic bead isolation (Chen, Chen, Narasaraju, Jin, \& Liu, 2004), have been unsuccessful, most likely due to the detrimental effect of the digestion process, which destroyed surface markers, a phenomenon reported previously (Gedye et al., 2014).

\section{Critical Parameters and Troubleshooting}

These protocols are particularly suited to institutes without live animal facilities and those with easy access to slaughter facilities, such as abattoirs and fallen stock services.

The ATII cell is reported to be the stem cell of the alveolus (Barkauskas et al., 2013), acting as the progenitor cell of the differentiated ATI cell. A key finding has been the senescence of ATII cells at passage 10-12.
Replicative senescence was first reported by Hayflick (1965), describing the processes by which cultured primary human cells undergo only a limited number of passages before losing their proliferative capacity. For this reason, studies using primary ATII cells isolated from adult bovine lungs should only be performed on cells up to passage 9. Furthermore, as senescent cells can be assumed to be more prevalent with age, younger donor animals should give higher yields of ATII cells (Katsara et al., 2011; Zaim, Karaman, Cetin, \& Isik, 2012).

Another consideration is the use of basic techniques to isolate ATII cells. The reason for this is the detrimental effect of enzymatic digestion upon cell surface markers. The binding of debris to the ATII marker CD74 in both FACS and magnetic bead isolation has been reported (Lee et al., 2018). Changing the recipe of the digestion mix is not advised, due to the high content of collagen previously reported in bovine lungs (Cohen, Zelikoff, \& Schlesinger, 2000) and the improved yield as a result of the inclusion of trypsin (Dobbs et al., 1986). However, there is merit to the theory that refinement of the isolation technique by downstream (passage 1 or later) magnetic bead or FACS methods will remove contaminating cells and improve purity of the culture.

Particular care should be taken when pouring Percoll gradients. When overlaying the $10 \%$ solution onto the $30 \%$ solution, there is a risk of the gradients mixing at the interface. This will affect the quality of the gradient and cause cells to form a smear against the side of the tube rather than a distinct band at the interface. It is recommended that one practice the
Lee and Chambers 
technique prior to the day of isolation and also pour more gradients than required in order to afford the luxury of choosing the most distinct layers.

Guidelines on the characterization of ATII cells isolated from bovine lungs can be found in Lee et al. (2018). Studying the expression of ATII biomarkers is useful for initial analysis; however, differentiation under two-dimensional submerged culture conditions will affect the number of ATII cells observed, since these conditions accelerate the differentiation of ATII into ATI cells. This differentiation is in part reversible in vitro by culturing the ATII cells in Matrigel (100\%; BD Biosciences) or on Matrigel-coated permeable membranes as polarized monolayers. Under these conditions, expression of the ATII markers CD74 and proSP-C is retained (Lee et al., 2018; Wang et al., 2007), along with the formation of lamellar inclusion bodies, the hallmark identifier of ATII cells in vitro and in vivo (Dobbs, Pian, Maglio, Dumars, \& Allen, 1997; Lee et al., 2018; Mao et al., 2015). Thus, if the ATII phenotype is lost during routine culture of cell stocks, a subculture can be grown as outlined above to assess phenotype. ATII cells can also be cultured as submerged 2D monolayers prior to studies performed on Transwell inserts. Although the ATII phenotype is lost in the former, it can be resurrected in the latter, as evidenced by immunofluorescence and transmission electron microscopy (Lee et al., 2018). The reversibility of differentiation is not a new discovery. It has been well documented that ATII cells lose such morphological characteristics as lamellar inclusion bodies and microvilli over a period of 1-7 days when grown on uncoated tissue culture plastic (Dobbs, 1990), but subsequent culture of seemingly differentiated cells results in reversal or de-differentiation, restoring the expression of ATII markers such as surfactant proteins A and C (SP-A and SP-C) (Dobbs et al., 1997; Wang et al., 2007).

Fungal contamination is an occupational hazard when isolating cells from organs exposed to the external environment. Amphotericin B may be effective in controlling fungal infection; however, it should be borne in mind that epithelial cells are also affected. If the source of tissue results in repeated failures due to fungal infection, it is recommended to plate cells in six-well plates and monitor cultures twice daily under a light microscope for signs of infection (fibrous mycelium). Wells that are infected may be treated with amphotericin B at a high dose by replacing the medium with amphotericin B stock solution $(250 \mu \mathrm{g} / \mathrm{ml})$ and leaving it in situ for about one hour. This effectively sacrifices that well, but neighboring wells are unaffected by this high concentration.

In summary, we offer the following suggestions: (1) freeze stocks to maximize the number of cells generated by one isolation, (2) restrict studies to cells cultured up to passage 9, (3) perform fibroblast removal on cells to be used in studies requiring a pure culture, and (4) be vigilant about infection, culturing in the presence of antibiotics for at least one week after isolation.

\section{Anticipated Results}

Cells isolated using these procedures should form a cobblestone morphology indicative of epithelial cells and exhibit markers characteristic of the ATII phenotype, including proSP-C, CD74, cytokeratin 18, and epithelial cell adhesion molecule (EpCAM). Differentiation of ATII cells into ATI cells may be studied by following the expression of the ATI marker aquaporin 5 (Aqp5). The increase of AQP5 mRNA expression is concomitant with a corresponding decrease in SFTPC in submerged 2D cultures over time, a key indicator of the dynamic and inverse relationship between these two cell markers (Kondo, Miyoshi, Sakiyama, Tangoku, \& Noma, 2015; Lee et al., 2018).

\section{Time Considerations}

Half a day should be set aside to prepare solutions in advance, with the exception of those stated above. When performed by experienced personnel, the isolation protocol takes $\sim 7 \mathrm{hr}$ from receipt of lungs to seeding of isolated cells. The time taken to transport the lungs from the point of slaughter to the laboratory should also be taken into account. A class II microbiological safety cabinet is necessary for the dissection procedure to maintain sterility.

Collection of lungs is dependent upon the distance of the slaughter facility from the laboratory. It can take up to 7 days for isolated cells to reach confluence, although this has been achieved in as little as 4 days.

\section{Acknowledgments}

This protocol forms part of a study supported by a strategic grant awarded by the National Centre for the Replacement, Refinement and Reduction of Animals in Research (NC3Rs; NC/M002047/1). We would like to thank members of the Veterinary Pathology Centre and the Biochemical Sciences \&
Lee and Chambers 
Bioimaging Core Facility at the University of Surrey for their assistance in the isolation procedure.

\section{Literature Cited}

Barkauskas, C. E., Cronce, M. J., Rackley, C. R., Bowie, E. J., Keene, D. R., Stripp, B. R., ... Hogan, B. L. (2013). Type 2 alveolar cells are stem cells in adult lung. Journal of Clinical Investigation, 123(7), 3025-3036. doi: 10.1172/ JCI68782.

Chen, J., Chen, Z., Narasaraju, T., Jin, N., \& Liu, L. (2004). Isolation of highly pure alveolar epithelial type I and type II cells from rat lungs. $L a b$ oratory Investigation; A Journal of Technical Methods and Pathology, 84(6), 727-735. doi: 10.1038/labinvest.3700095.

Cohen, M. D., Zelikoff, J. T., \& Schlesinger, R. B. (2000). Pulmonary immunotoxicology. New York, NY: Springer U.S.

Dobbs, L. G. (1990). Isolation and culture of alveolar type II cells. American Journal of Physiology, 258(4 Pt 1), L134-147. doi: 10.1152/ ajplung.1990.258.4.L134.

Dobbs, L. G., Gonzalez, R., \& Williams, M. C. (1986). An improved method for isolating type II cells in high yield and purity. American Review of Respiratory Disease, 134(1), 141-145. doi: 10.1164/arrd.1986.134.1.141.

Dobbs, L. G., Pian, M. S., Maglio, M., Dumars, S., \& Allen, L. (1997). Maintenance of the differentiated type II cell phenotype by culture with an apical air surface. American Journal of Physiology, 273(2 Pt 1), L347-354. doi: 10.1152/ ajplung.1997.273.2.L347.

Driscoll, K. E., Carter, J. M., Iype, P. T., Kumari, H. L., Crosby, L. L., Aardema, M. J., ... Burns, J. L. (1995). Establishment of immortalized alveolar type II epithelial cell lines from adult rats. In Vitro Cellular \& Developmental Biology. Animal, 31(7), 516-527. doi: 10.1007/ BF02634029.

Ehrhardt, C., Kim, K. J., \& Lehr, C. M. (2005). Isolation and culture of human alveolar epithelial cells. Methods in Molecular Medicine, 107, 207-216.

Fehrenbach, H. (2001). Alveolar epithelial type II cell: Defender of the alveolus revisited. Respiratory Research, 2(1), 33-46. doi: 10.1186/rr36.

Fujino, N., Kubo, H., Suzuki, T., Ota, C., Hegab, A. E., He, M., ... Yamaya, M. (2011). Isolation of alveolar epithelial type II progenitor cells from adult human lungs. Laboratory Investigation; A Journal of Technical Methods and Pathology, 91(3), 363-378. doi: 10.1038/labinvest. 2010.187 .

Gedye, C. A., Hussain, A., Paterson, J., Smrke, A., Saini, H., Sirskyj, D., .. Ailles, L. E. (2014). Cell surface profiling using high-throughput flow cytometry: A platform for biomarker discovery and analysis of cellular heterogeneity. PLoS One, 9(8), e105602. doi: 10.1371/journal. pone. 0105602 .

Gereke, M., Autengruber, A., Gröbe, L., Jeron, A., Bruder, D., \& Stegemann-Koniszewski, S.
(2012). Flow cytometric isolation of primary murine type II alveolar epithelial cells for functional and molecular studies. Journal of Visualized Experiments: JoVE (70), e4322. doi: $10.3791 / 4322$.

Gonzalez, R. F., \& Dobbs, L. G. (2013). Isolation and culture of alveolar epithelial type I and type II cells from rat lungs. Methods in Molecular Biology, 945, 145-159. doi: 10.1007/978-1-62703-125-7_10.

Hayflick, L. (1965). The limited in vitro lifetime of human diploid cell strains. Experimental Cell Research, 37, 614-636. doi: 10.1016/0014-4827(65)90211-9.

Katsara, O., Mahaira, L. G., Iliopoulou, E. G., Moustaki, A., Antsaklis, A., Loutradis, D., ... Perez, S. A. (2011). Effects of donor age, gender, and in vitro cellular aging on the phenotypic, functional, and molecular characteristics of mouse bone marrow-derived mesenchymal stem cells. Stem Cells and Development, 20(9), 1549-1561. doi: 10.1089/scd. 2010.0280 .

Kondo, H., Miyoshi, K., Sakiyama, S., Tangoku, A., \& Noma, T. (2015). Differential regulation of gene expression of alveolar epithelial cell markers in human lung adenocarcinoma-derived A549 clones. Stem Cells International, 2015, 165867. doi: 10.1155/2015/165867.

Lee, D. F., Salguero, F. J., Grainger, D., Francis, R. J., MacLellan-Gibson, K., \& Chambers, M. A. (2018). Isolation and characterisation of alveolar type II pneumocytes from adult bovine lung. Scientific Reports, 8(1), 11927. doi: 10.1038/s41598-018-30234-x.

Lee, J. H., Kim, J., Gludish, D., Roach, R. R., Saunders, A. H., Barrios, J., ... Kim, C. F. (2013). Surfactant protein-C chromatin-bound green fluorescence protein reporter mice reveal heterogeneity of surfactant protein C-expressing lung cells. American Journal of Respiratory Cell and Molecular Biology, 48(3), 288-298. doi: 10.1165/rcmb.2011-0403OC.

Mao, P., Wu, S., Li, J., Fu, W., He, W., Liu, X., . . . Li, Y. (2015). Human alveolar epithelial type II cells in primary culture. Physiological Reports, 3(2), e12288. doi: 10.14814/phy2.12288.

Pal, K., \& Grover, P. L. (1983). A simple method for the removal of contaminating fibroblasts from cultures of rat mammary epithelial cells. Cell Biology International Reports, 7(10), 779-783. doi: 10.1016/0309-1651(83)90181-9.

Pertoft, H., Laurent, T. C., Låås, T., \& Kågedal, L. (1978). Density gradients prepared from colloidal silica particles coated by polyvinylpyrrolidone (Percoll). Analytical Biochemistry, 88(1), 271-282. doi: 10.1016/0003-2697(78) 90419-0.

Phelps, D. S., \& Floros, J. (1991). Localization of pulmonary surfactant proteins using immunohistochemistry and tissue in situ hybridization. Experimental Lung Research, 17(6), 985-995. doi: 10.3109/01902149109064330.

Wang, J., Edeen, K., Manzer, R., Chang, Y., Wang, S., Chen, X., ... Mason, R. J. (2007).
Lee and 
Differentiated human alveolar epithelial cells and reversibility of their phenotype in vitro. American Journal of Respiratory Cell and Molecular Biology, 36(6), 661-668. doi: 10. 1165/rcmb.2006-0410OC.

World Health Organization (WHO). (2017). Global tuberculosis report 2017. Geneva: World Health Organization.

Wysocki, L. J., \& Sato, V. L. (1978). "Panning" for lymphocytes: A method for cell selection. Proceedings of the National Academy of Sciences of the United States of America, 75(6), 2844-2848. doi: 10.1073/pnas.75.6.2844.
Zaim, M., Karaman, S., Cetin, G., \& Isik, S. (2012). Donor age and long-term culture affect differentiation and proliferation of human bone marrow mesenchymal stem cells. Annals of Hematology, 91(8), 1175-1186. doi: 10.1007/s00277-012-1438-x.

\section{Key Reference}

Lee et al. (2018). See above.

This article outlines the isolation protocol in brief and includes data appertaining to the initial characterization of ATII cells. This includes morphology by light microscopy, mRNA expression, and phenotype by immunofluorescence. 